\title{
AS LUTAS E CONQUISTAS DAS QUEBRADEIRAS DE COCO DO BICO DO PAPAGAIO EM "RAIMUNDA, A QUEBRADEIRA"
}

\section{THE STRUGGLES AND CONQUESTS OF WOMEN EXTRACTIVE IN BABAÇU COCO IN THE BICO DO PAPAGAIO REGION IN “RAIMUNDA, AQUEBRADEIRA”}

Milena Botelho Azevedo Lena ${ }^{1}$

\begin{abstract}
RESUMO
Durante décadas, as mulheres quebradeiras de coco da região do Bico do Papagaio, extremo Norte do Tocantins, mobilizaram-se para transformar a realidade social da região. Defensoras do extrativismo, da agroecologia e da organização comunitária, elas ainda lutam para dar visibilidade à realidade enfrentada no dia a dia durante o trabalho da quebra do coco babaçu nesse território. Até hoje, a prática da quebra de coco é ameaçada constantemente por fatores ligados ao agronegócio e o acesso pelos donos das fazendas ou mesmo a baixa competitividade dos produtos oriundos do babaçu. Isso posto, este artigo traz uma discussão com viés metodológico exploratório construída a partir da literatura e do documentário Raimunda, a Quebradeira, com foco no extrativismo do babaçu e na participação feminina, com destaque para a líder das quebradeiras de coco, dona Raimunda Gomes da Silva, que contribuiu com as reflexões sobre as dinâmicas das relações sociedade-natureza no Bico do Papagaio, região norte do Estado do Tocantins.
\end{abstract}

PALAVRAS-CHAVE: Agroecologia. Protagonismo feminino. Tocantins. Extrativismo.

\begin{abstract}
For decades, women coconut breakers in the region of Bico do Papagaio, in the far north of Tocantins, have mobilized to transform the social reality of the region. Defenders of extractivism, agroecology and community organization, they still struggle to give visibility to the reality they face on a daily basis while working to break the babassu coconut in this territory. Until today, the practice of coconut breaking is constantly threatened by factors related to agribusiness and access by farm owners or even the low competitiveness of products from babassu. That said, this article brings a discussion with an exploratory methodological bias built from the literature and documentary Raimunda, a Quebradeira, with a focus on babaçu extractivism and female participation, with emphasis on the leader of the coconut breakers, Mrs. Raimunda Gomes da Silva, who contributed with reflections on the dynamics of naturesociety relations in Bico do Papagaio, northern region of the State of Tocantins.
\end{abstract}

KEYWORDS: Agroecology. Female protagonism. Tocantins. Extractivism.

\footnotetext{
${ }^{1}$ Mestre em Comunicação e Sociedade pela Universidade Federal do Tocantins - UFT. Graduada em Comunicação Social - Habilitação em Jornalismo (Rádio e TV), pela Universidade do Tocantins (UNITINS) Pós-Graduação em Comunicação Empresarial e Marketing, pela Fundação Universidade do Tocantins (UNITINS) Pós-graduanda em Comunicação, Sociedade e Meio Ambiente pela Universidade Federal do Tocantins (UFT)
} 


\section{INTRODUÇÃO}

Novos papeis e lugares foram dados às mulheres na sociedade contemporânea. As últimas décadas foram caracterizadas por mudanças profundas que afetaram a vida das mulheres. Por exemplo, a realização dos direitos de voto das mulheres e uma forte penetração no mercado de trabalho, mas ainda existe muito a discutir e a percorrer quando o assunto é igualdade de gênero. Muitas das vezes os salários entre homens e mulheres são desiguais. Mesmo que as mulheres representem uma maior parcela na população, em muitos espaços são encontradas em minoria, a exemplo da representatividade parlamentar. Lutar pelos direitos da mulher é permanente, e nesse âmbito, aspectos econômicos, sociais e culturais não podem ser deixados de lado (DAVIS, 2016; LENA; PÔRTO JÚNIOR, 2018).

Por décadas, as famílias brasileiras viveram assim e as pessoas viam as mulheres dessa forma. No extremo norte do Estado do Tocantins, na região do Bico do Papagaio, algumas mulheres resolveram quebrar o preconceito de que as mulheres não podem ocupar espaços sociais fora da família, e enfrentam o desafio de ocupar outros espaços, até mesmo em termos de renda familiar, o famoso papel do ganha-pão. Nesse período, a imagem masculina ainda era proeminente e dominava a tomada de decisões da família e até da comunidade, pois a cultura local ainda acreditava que as mulheres eram desamparadas e incapazes de galgar o próprio espaço. Devido a muitos desses aspectos estarem profundamente arraigados, fazem com que as mulheres que vivem nessas comunidades raramente participem de atividades coletivas de produção ou participem do espaço de discussão e tomada de decisões na comunidade, pois para essa abordagem, existe o trabalho "extra casa", o que é para muitas famílias ainda um desafio moral (ROCHA, 2011; PIZZIO; CECCHIN, 2015; BRITO; ALMEIDA, 2017; LENA; PÔRTO JÚNIOR, 2020).

A região do Bico do Papagaio, situada no norte do Estado do Tocantins configura-se como um espaço de confluência com os estados do Maranhão e do Pará. Neste território, uma variedade de situações em áreas rurais, afetadas por fatores endógenos e exógenos são apresentadas, além do avanço das fronteiras agrícolas na região, lutas e conflitos pela terra, planos e projetos de governo etc. O Bico do Papagaio faz parte da zona de fronteira e deu-lhe uma certa singularidade. Isso porque, como outros pesquisadores já comprovaram, esse é um fenômeno que leva à reorganização do espaço nacional repleto de complexos processos sociais, econômicos e políticos (DUVERNOY, 1994; FOWERAKER, 1982; MARTINS, 1997). 
Durante décadas, as trabalhadoras rurais da região do Bico do Papagaio, se mobilizaram para mudar a realidade social da região. Nos últimos anos, elas têm sido defensoras do extrativismo, da agroecologia e das organizações comunitárias, e suas lutas têm sido reconhecidas pela sociedade e pelo poder público. As mulheres extrativistas do coco babaçu, conhecidas como quebradeiras de coco babaçu, possuem importante papel histórico, econômico, social, político, ambiental e cultural na chamada "região dos babaçuais". Mais de 400.000 mulheres do extrativismo agrícola participaram da extração do coco babaçu, mas essa atividade está constantemente sob ameaça, seja para impedir que essas mulheres entrem em contato com os babaçus, seja pela expansão do agronegócio em áreas dominadas por babaçu; ou pela dificuldade da venda dos produtos dos oriundos do babaçu.

Figura 1 - Na região do Bico do Papagaio, mulheres lutam para ter acesso às terras para extrair o coco babaçu.

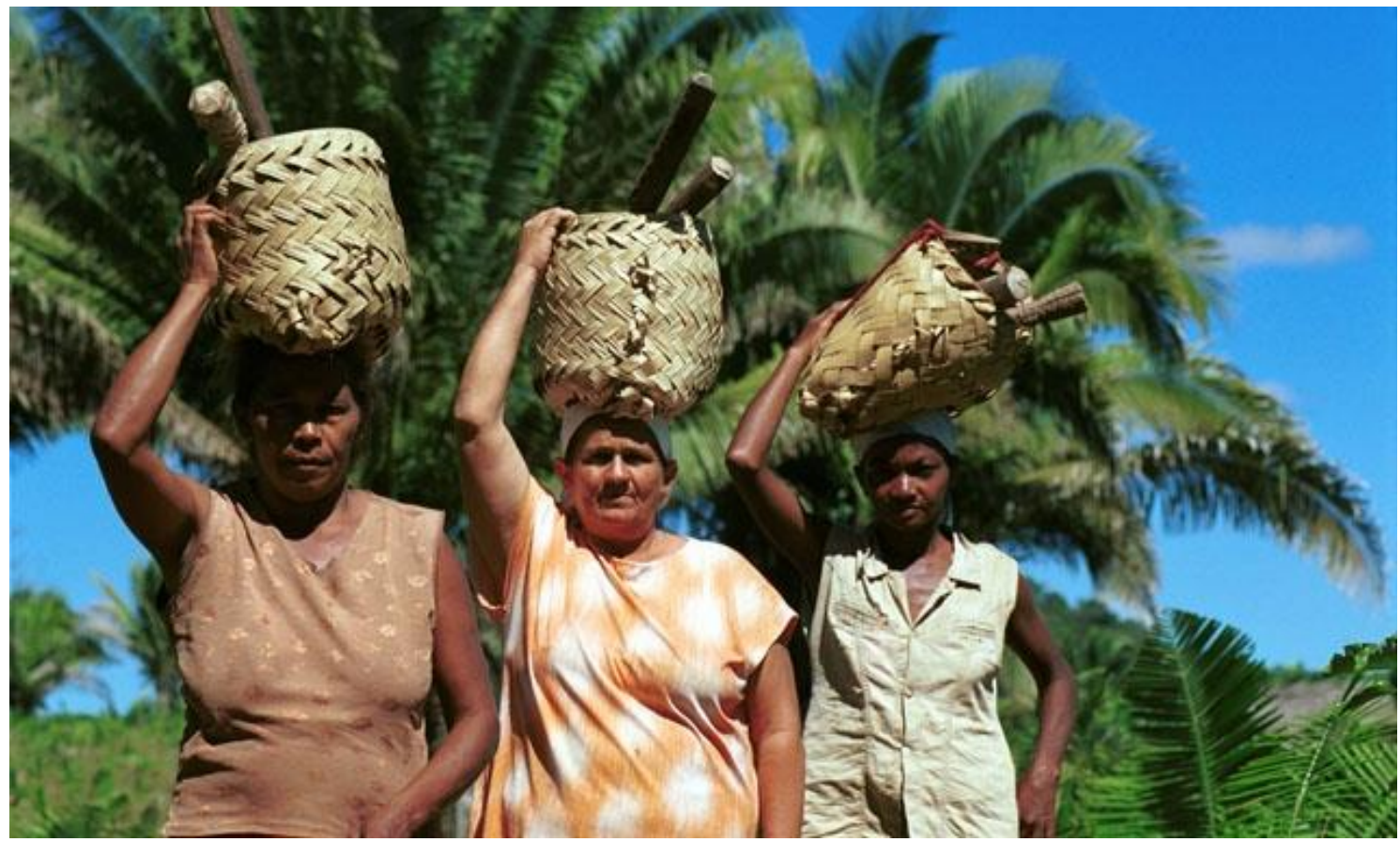

Fonte: Material de divulgação do Documentário Raimunda, a quebradeira

Embora muitas pesquisas tenham sido realizadas nos últimos anos, com abordagens distintas, sobre o trabalho, a cultura e tradição, relação social, proteção dos saberes, entre outros aspectos do cotidiano das quebradeiras de coco babaçu, cabe empreender discussões teóricas e 
empíricas com foco nas lutas, direitos e conquistas dos grupos de mulheres espalhadas pelos estados brasileiros (NUNES, 2020), em especial no Tocantins.

Isso posto, este artigo traz uma discussão com viés metodológico exploratório construída a partir da literatura e do documentário Raimunda, a quebradeira, dirigido por Marcelo Silva e que foi vencedor da etapa tocantinense do DoCTV III, promovido pelo Ministério da Cultura.

Figura 2 - Dona Raimunda, líder e representante das mulheres extrativistas de coco babaçu do Bico do Papagaio.

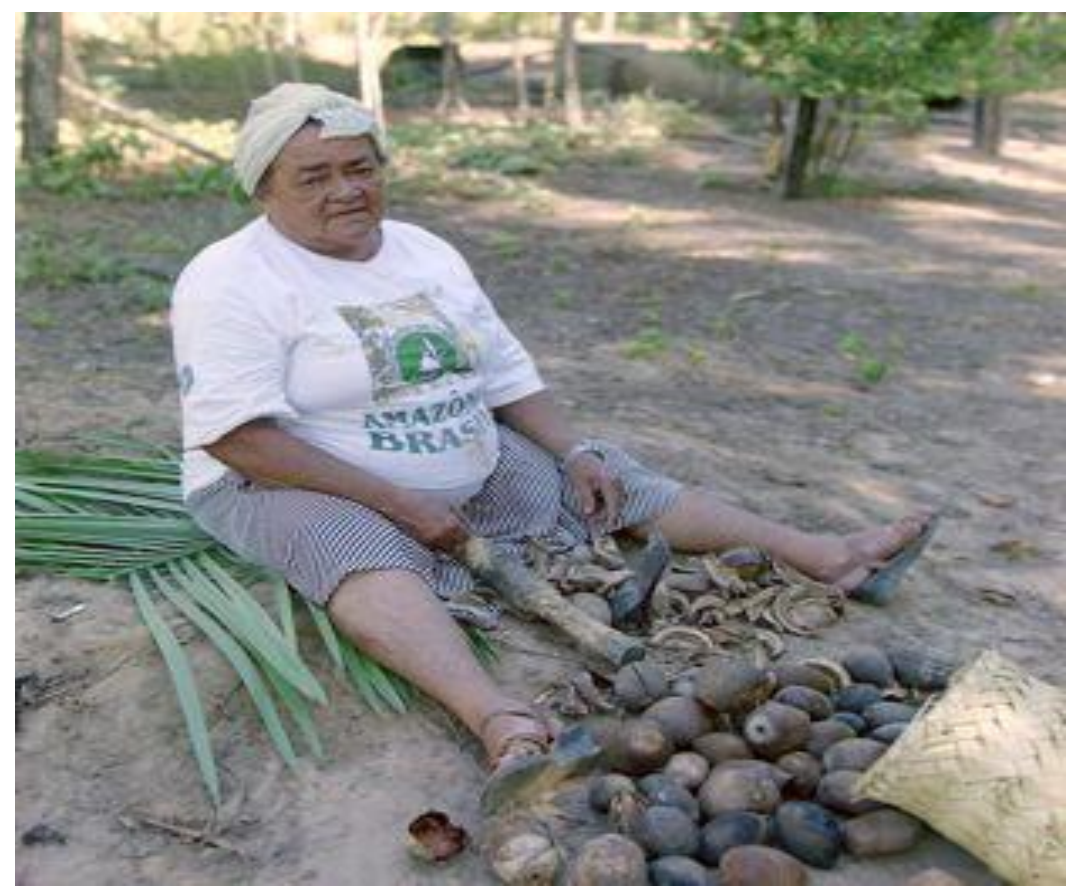

Fonte: Material de divulgação do Documentário Raimunda, a quebradeira.

Lançado em 2007, o audiovisual apresentou a história das quebradeiras de coco da região do Bico do Papagaio do Estado do Tocantins, por meio da trajetória da Dona Raimunda, que, em conjunto com outros representantes locais, deu início ao Movimento Interestadual das Quebradeiras de Coco Babaçu (MIQCB). Esse movimento teve como principal pauta a luta para que as quebradeiras de coco pudessem ter acesso às terras públicas e privadas que continham a palmeira do coco babaçu; e para que as palmeiras não fossem derrubadas. Com foco no extrativismo do babaçu e na participação feminina como marco para as reflexões sobre as dinâmicas das relações sociedade-natureza no Bico do Papagaio, o artigo objetiva-se 
averiguar se a produção do documentário conferiu visibilidade à região e às quebradeiras e, ao mesmo tempo, a Dona Raimunda, enquanto líder e representante das mulheres extrativistas de coco babaçu. O estudo discorre na parte teórica sobre a região do Bico do Papagaio como território de pertencimento. A segunda denominada de extração do babaçu trata de uma discussão teórica baseada no referido documentário.

\section{Bico do Papagaio como Território de Pertencimento das Quebradeiras de Coco}

A região do Bico do Papagaio constitui-se em uma área de fronteira entre os estados do Pará, Maranhão e Tocantins. Situada no norte do Estado do Tocantins, próximo às margens dos rios Araguaia e Tocantins, cujo formato da confluência, lhe inspirou o nome Bico do Papagaio.

Essa região, tem sua dinâmica de ocupação territorial ligada à presença de indígenas e quilombolas, além dos migrantes das frentes de expansão mais antiga, formada por trabalhadores dos estados do Nordeste, como Maranhão, Ceará e Piauí. Famílias que buscavam terras desocupadas para a prática da agricultura e do extrativismo, consolidando a dinâmica de produção de subsistência que caracteriza a região (SOUSA; SILVA, 2017; VIEIRA, 2018). Conforme análises dos autores Rocha (2011) e Vieira (2018), neste território as dinâmicas socioambientais são diferenciadas, como a do extrativismo do babaçu, além de se encontrar na área de expansão da fronteira agrícola brasileira, em direção à Amazônia. Por essa razão, a região foi alvo de fortes investimentos, políticas de incentivos produtivos e fiscais, principalmente a partir das décadas de 1960 e 1970, período da ditadura militar no Brasil, além da ação de grileiros, que se apropriaram de vastas extensões de terra na região.

Figura 3 - No Bico do Papagaio, atividade extrativa do babaçu traz renda para as famílias da região. 


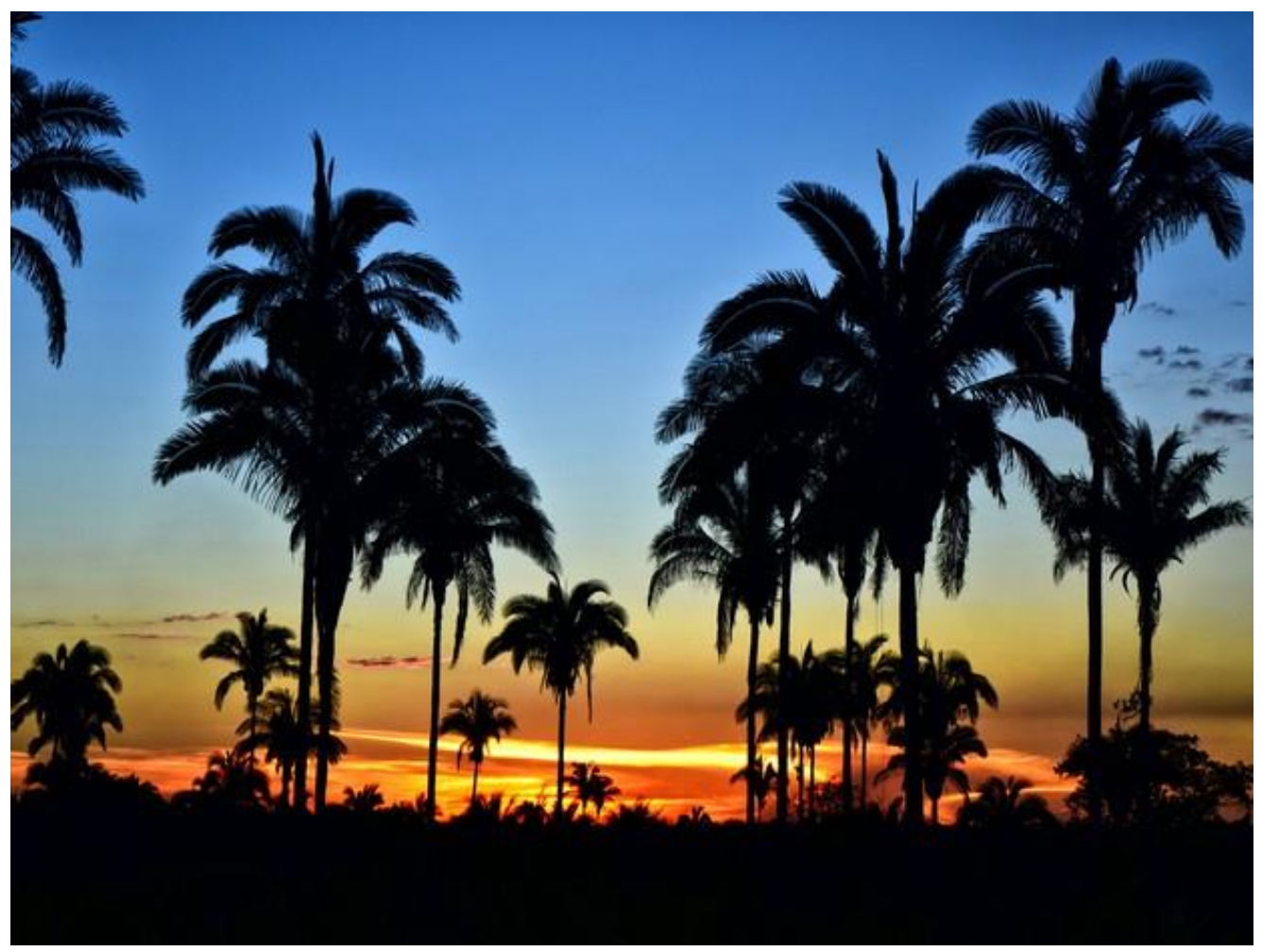

Fonte: Material de divulgação do Documentário Raimunda, a quebradeira.

A região, por fazer parte de uma região de fronteira, já lhe confere certas singularidades (ROCHA, 2011; PIZZIO; CECCHIN, 2015; BRITO; ALMEIDA, 2017; LENA; PÔRTO JÚNIOR, 2018). Isto porque, conforme pode ser atestado pela literatura, esse é um fenômeno responsável pela reorganização do espaço nacional recheado de inúmeros e complexos processos sociais, econômicos e políticos (FOWERAKER, 1982).

Um dos aspectos que distingue a agricultura familiar, conciliada com as lides agrícolas, fazendo parte da vida desses segmentos de agricultores. $\mathrm{O}$ babaçu contribui significativamente para a reprodução social e econômica dessas famílias. Assim, a presente proposta de pesquisa concentra-se no extrativismo do babaçu e na participação feminina como marco para as reflexões sobre as dinâmicas das relações sociedade-natureza no Bico do Papagaio, região localizada no extremo norte do estado do Tocantins.

Para Martins (1997), a fronteira é um local de conflito social que faz parte do processo de incorporação capitalista, onde os pequenos agricultores da frente demográfica, após limparem a terra e tornarem as áreas prontas para a produção de mercadorias, são expulsos pela chegada do capital empresarial, seja por meio da violência direta ou pela dinâmica de desenvolvimento econômico que se instala. Martins também afirma serem esses espaços um 
lugar de contradições, pode-se afirmar que o Bico do Papagaio é um lugar de encontros e desencontros e nele se estabelecem novas relações marcadas por confrontos entre grupos humanos com diferentes visões de mundo.

Segundo Hébette e Acevedo (1979) essa era uma região considerada socialmente e economicamente pobre, que possuía uma estrutura produtiva predominantemente rural sendo que nos últimos 50 anos, tem sofrido profundas transformações tendo como principais fatores de modificação a abertura da rodovia BR 153 (Belém-Brasília), a expansão da fronteira agrícola a partir do sudoeste do Maranhão e sudeste do Pará, a abertura da rodovia Transamazônica e a grande expansão das atividades pecuárias extensivas, principalmente do norte goiano.

Para Santos (2015) e Kopenawa e Albert (2015) o ocorrido pode ser caracterizado por um processo de colonização, em que é definido por (SANTOS, 2015, p.47-48) como sendo "todos os processos etnocêntricos de invasão, expropriação, etnocídio, subjugação e até de substituição de uma cultura pela outra, independentemente do território físico geográfico em que essa cultura se encontra". Cabe frisar que os valores socioculturais e a relação dos povos tradicionais com a terra, o lugar de pertencimento deve ser respeitado, com o intuito de preservar sua identidade enquanto povo de um território (SANTOS, 2015; KOPENAWA; ALBERT, 2015; VIVEIROS DE CASTRO, 2017). Santos (2007) defende que a trajetória desses povos é visível e palpável materialmente e pode ser sentida imaterialmente, tanto quando se olha para o passado e faz-se referência aos seus ancestrais, como hoje quando se visita as comunidades da atualidade e existe um diálogo com as suas organizações e manifestações culturais.

Conforme demonstrado por Clementino e Monte-Mór (2004), o Bico do Papagaio, refere-se a uma região que possui a maior área de ocorrência de babaçu, um espaço onde se manifestam dinâmicas socioambientais bastante diferenciadas, e que tem sido alvo de diversas políticas públicas (agrícolas, energéticas, ambientais, de integração territorial, de transportes, etc.); e, pela retomada dos grandes projetos planejados durante os governos militares, bem como novos projetos e programas elaborados e implementados, por agências governamentais e privadas.

As dinâmicas socioambientais são marcadas por disputas em torno da posse e uso dos "recursos" naturais (terra, recursos extrativistas e outros) entre diferentes atores sociais, dentre eles, os agroextrativistas, associando-se à privatização das terras, ao cercamento das áreas, à 
proibição e/ou limitação de acesso ao babaçu e à substituição da biodiversidade pelos campos de pastagem homogênea (LENA; PÔRTO JÚNIOR, 2020). Oliveira (2020, p. 43) corrobora que o território pode ser visto como um palco onde existem relações de poder, o que inclui as multiplicidades de atores sociais, políticos e econômicos. O território na visão do autor é "o trabalho, o lugar da residência, das trocas materiais e espirituais e do exercício da vida".

Cabe destacar que esses processos promovem mudanças significativas nas paisagens locais que compõem a vasta área do Bico do Papagaio (LENA; PÔRTO JÚNIOR, 2018), afetando de forma direta a relação de pertencimento e de identidade da comunidade local (OLIVEIRA, 2020). Contudo, também afeta a agricultura familiar, uma categoria socioprodutiva, que possui um peso significativo nestas disputas, bem como na configuração e transformação desse espaço, haja vista os diversos segmentos de famílias que abrange (LENA; PÔRTO JÚNIOR, 2020; NUNES, 2020), por exemplo, os assentados rurais, os parentes dos assentados que moram e cultivam na terra dos parentes, os pequenos proprietários de terra, os herdeiros de terra sem partilha e os trabalhadores rurais sem terras.

Em função da grande abrangência da região e das configurações que esta assume no processo de ocupação, que pode ser dividida em duas frentes, norte e sul, com características bem distintas, se faz necessário definir um espaço geográfico para a discussão teórica. Assim, essa discussão considerou o lócus espacial norte, correspondente a área geográfica que abrange os municípios de São Miguel do Tocantins; Sítio Novo do Tocantins, Praia Norte, Carrasco Bonito, Buriti do Tocantins; Axixá do Tocantins; Esperantina e Augustinópolis (CLEMENTINO; MONTE-MÓR, 2004).

Essa região é composta por diversos elementos que alojam rótulos "sociais", “econômicos", “ambientais", "políticos", "técnicos" e outros que interagem entre si em uma rede sociotécnica definida sobre aspectos estes que são característicos de um território. Também por se tratar de um espaço onde a atividade agroextrativista (roça e babaçu) se sobressai enquanto estratégia alternativa de produção e fortalecimento da agricultura familiar, bem como da dinâmica socioambiental da região.

As formas de ocupação e povoamento dessa região foram determinadas quase sempre pela disponibilidade de terras livres (terras devolutas do estado do Goiás), de pastos naturais e pelas condições edafoclimáticas, em especial, pelo ecossistema de mata de transição entre a Floresta Amazônica e o Cerrado, que proporciona um clima caracterizado como tropical 
úmido à subúmido, com duas estações definidas: chuvosa, também chamada de inverno, de outubro a abril; e seca, também chamada de verão, de maio a setembro, favorecendo a criação extensiva do gado, planejamento do calendário agrícola e do extrativismo. Outros recursos como solos, vegetação e hídricos também foram considerados fundamentais no processo de ocupação desses espaços. Pela estreita relação entre produção agroextrativista e tipos de solos e recursos vegetais, os primeiros lugares a serem ocupados foram às margens do rio Tocantins, considerado terreno fértil, drenado e propício ao trabalho agrícola.

Com fertilidade natural, consideradas como boas terras, terras férteis devido ao solo e a abundância de certas riquezas vegetais foram os fatores que inicialmente atraíram as populações migrantes, procedentes, sobretudo, do Maranhão, para aí construírem e organizarem espacialmente a região mais dinâmica do estado do Tocantins. (BARBOSA et al., 2004, p. 116).

Foi a partir desses fatores que esta região passou a sofrer grandes modificações em sua base produtiva. De acordo com o pesquisador Miranda Neto (1991), os programas governamentais implantados nos anos de 1970, como o Polamazônia e o Polocentro, e o Plano de Integração Nacional (PIN), que prioriza a implantação de grandes projetos na Amazônia como um todo: rodoviários (Transamazônica, Perimetral Norte e outras), de colonização (agrovilas), agrominerais, agropecuários e industriais, implementados por grandes empresas nacionais e multinacionais. Portanto, esses projetos que visavam à integração da região amazônica ao resto do país, com base em incentivos fiscais às grandes empresas do capital comercial e financeiro, promoveram o aumento da fronteira, acelerando o processo de modernização com a introdução de novas tecnologias.

Com o processo de ocupação da região um fator relevante, entre tantos outros, foi definido pelas características dos sistemas de produção que ajudaram na constituição de núcleos permanentes de povoamento naquele espaço. Estes sistemas de produção se relacionavam e estavam, de certa forma, articulados com determinadas unidades de paisagens ou ecopaisagens da região e por estratégias diferenciadas de uso da base dos elementos naturais presentes em cada uma dessas unidades, dos quais destacam-se três sistemas de produção que marcaram com maior profundidade a ocupação desta região: a pecuária, o extrativismo e a agricultura de subsistência (SOARES, 2009).

O autor Soares (2009) destaca que cada sistema foi responsável pela definição das estratégias de ocupação e conformação da região. A pecuária foi utilizada como estratégia de 
ocupação dos campos cerrados; o extrativismo de produtos como o caucho, a castanha e o babaçu, associado à caça, como estratégia de utilização dos recursos das florestas; e a agricultura de subsistência, associada principalmente aos cultivos de arroz e da mandioca, baseada no sistema de corte e queima, como meio de reprodução da fertilidade do solo. Esses sistemas de produção determinaram as formas de exploração dos elementos naturais (SOARES, 2009).

Nesse sentido, os sistemas pecuária de pequena escala, extrativismo e agricultura de subsistência, associam-se para formar o sistema agroextrativista, onde cada uma dessas atividades participa à sua maneira, nas devidas proporções, do conjunto de atividades produtivas destinadas à reprodução familiar.

Historicamente populações locais compostas na sua grande maioria por indígenas, comunidades negras, camponeses, ribeirinhos, pescadores artesanais, quebradeiras de coco babaçu etc. vêm se utilizando do extrativismo dos diversos biomas brasileiros (Mata Atlântica, Mata dos Pinhais, Cerrado, Caatinga, Mata dos Cocais e Amazônia) como meio de garantir sua subsistência (NETO, 2017; SARAIVA et al., 2019). Aliás, o extrativismo vegetal teve suas origens, segundo Homma (1993), desde o aparecimento dos seres humanos na face da terra, há milhões de anos, assim, a presença de diferentes grupos ocupando e garantindo sua sobrevivência, a partir dos recursos da floresta é, quase sempre, uma regra (NUNES, 2020).

\section{Raimunda, a Quebradeira e as mulheres extrativistas do coco babaçu}

No extremo norte do Tocantins, em 2007, houve o registro de um documentário, denominado Raimunda, a Quebradeira (LENA; PÔRTO JÚNIOR, 2020), ao qual trouxe memórias de conflitos, conquistas e perdas pela extração do coco babaçu, com, principalmente, personagens femininas, empoderadas pela vontade de mudar de vida desde a década de 1980 . Assim, refere-se ao conteúdo social construído a partir de experiências consistentes e palpáveis que pode ser enquadrada pela história. É algo interno e pessoal e passível de ser explorada (DIEHL, 2000).

Figura 4 - Cartaz de divulgação do documentário Raimunda, a quebradeira. 


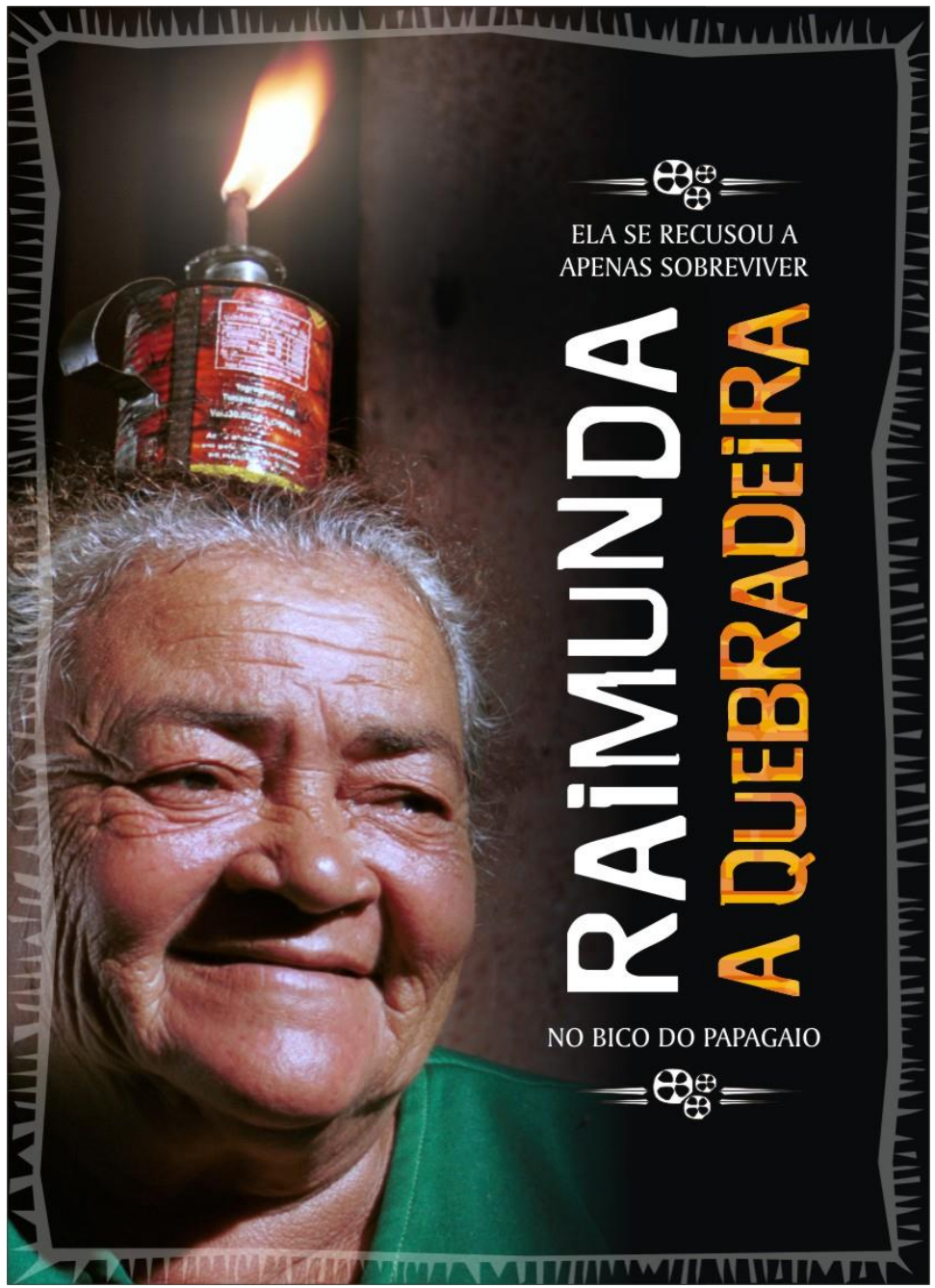

O grupo de mulheres, lideradas por uma mulher conhecida como Dona Raimunda, hoje falecida, baixinha e corpulenta, de traços fortes. Com um linguajar simples, que mescla fáceis temas cotidianos e toca em feridas sociais em seus discursos, esteja ela em comunidades agrícolas ou palácios de Governo, sem perder o tom diplomático. Nunca estudou, mas é uma líder nata, de visão política apurada, a qual será nossa principal personagem nessa narrativa de empoderamento feminino (RAIMUNDA, A QUEBRADEIRA, 2007).

Filha de agricultores pobres, nascidas no Maranhão em uma família de 10 irmãos. Casou-se aos 18 anos, mas em meio a uma relação difícil, decidiu abandonar o marido 14 anos depois e criar sozinha os seis filhos, trabalhando como lavradora. Na sua constante migração à procura de serviço, chegou ao Bico do Papagaio, região desassistida onde moravam 52 famílias. Para levar trabalho comunitário à região e proteger os moradores das ameaças de grileiros, 
começou a mobilizar companheiros para a criação de sindicatos rurais (RAIMUNDA, A QUEBRADEIRA, 2007).

No início da década de 80, quando Dona Raimunda passou a ser animadora e catequista da comunidade, ela pode expressar com mais clareza suas insatisfações e anseios. Com a chegada de um novo padre em 1983 na cidade de São Miguel, a militância de Dona Raimunda aflorou e ganhou mais espaço. O pároco se tratava de Josimo Tavares, assassinado três anos depois por fazendeiros e autoridades do Bico do Papagaio. Com a morte brutal do padre, a quebradeira começou a ganhar o mundo denunciando o crime contra o religioso e atuando na defesa das cerca de 400 mil mulheres que passou a representar. Raimunda estava à frente na criação da Associação das Mulheres Trabalhadoras Rurais do Bico do Papagaio (Asmubip); a Federação dos Trabalhadores na Agricultura do Estado do Tocantins (Fetaet) e a Secretaria da Mulher Extrativista do Conselho Nacional dos Seringueiros (CNS), da qual foi titular por dez anos (RAIMUNDA, A QUEBRADEIRA, 2007).

No decorrer da sua trajetória, outra vitória de dona Raimunda foi a aprovação, em 2008, de uma lei estadual, chamada de "Lei do Babaçu Livre", garantindo a não derrubada das palmeiras de babaçu - que os fazendeiros punham abaixo, queimavam ou envenenavam - e a permissão para as quebradeiras entrarem nas propriedades privadas para recolher os cocos babaçu que lhes rendem o sustento. O quilo do coco é vendido por aproximadamente $\mathrm{R} \$ 0,70$ e o litro do óleo do babaçu, por R \$ 3,50. Cada quebradeira consegue quebrar, no máximo, 10 quilos por dia. Muitos proprietários que expulsam as quebradeiras a tiros de suas terras. Há um projeto de lei federal como esse tramitando no Congresso desde 1995. Sem previsão de aprovação (RAIMUNDA, A QUEBRADEIRA, 2007).

\footnotetext{
Se, e quando, alguém conseguir acabar, do ponto de vista histórico, com os malentendidos sobre as experiências das mulheres negras escravizadas, ela (ou ele) terá prestado um serviço inestimável. Não é apenas pela precisão histórica que um estudo desses deve ser realizado; as lições que ele pode reunir sobre a era escravista trarão esclarecimentos sobre a luta atual das mulheres negras e de todas as mulheres em busca de emancipação. Como leiga, posso apenas propor algumas hipóteses que talvez sejam capazes de orientar um reexame da história das mulheres negras durante a escravidão (ANGELA DAVIS, 2016, p. 23).
}

Em 2003, Dona Raimunda recebeu o Prêmio Bertha Luz do Senado Federal por sua atuação na defesa dos direitos das mulheres extrativistas de coco, prêmio concedido a mulheres que contribuíram para a defesa dos direitos da mulher e das questões de gênero no Brasil. Em 2005, ela foi incluída na lista de 1.000 mulheres concorrentes ao Prêmio Nobel da 
Paz. Em 2009, recebeu o doutorado honorário pela Universidade Federal do Tocantins (UFT) e, em 2013, recebeu o Diploma Gilhemina Ribeiro da Silva, cidadã da Assembleia Legislativa do Tocantins (LENA; PÔRTO JÚNIOR, 2020).

Ao longo de décadas, as mulheres trabalhadoras rurais da região do Bico do Papagaio, mobilizaram-se para transformar a realidade social da região. Defensoras do extrativismo, da agroecologia e da organização comunitária, elas vêm tendo sua luta reconhecida pela sociedade e poder público nos últimos anos (PIZZIO; CECCHIN, 2015; BRITO; ALMEIDA, 2017).

As mulheres extrativistas de coco babaçu da região do Bico do Papagaio têm uma grande importância histórica, econômica, social, política, ambiental e cultural na chamada "região dos babaçuais", que engloba partes dos estados do Pará, Piauí, Maranhão e do Tocantins, abrangendo também os estados de Goiás e Mato Grosso, ao qual abrange centenas de mulheres agroextrativistas, que exercem a atividade de extrativismo do coco babaçu (ALMEIDA, 2008). Essa atividade das mulheres quebradeiras de coco é constantemente ameaçada, seja pelos fazendeiros e grandes proprietários de terras na região que tentam impedir o acesso delas aos babaçuais, pela expansão do agronegócio na região de predominância dos babaçuais, pela dificuldade da comercialização dos produtos oriundos do babaçu, ou pela dificuldade de acesso à terra e aos babaçuais, que garantem às quebradeiras a continuidade do seu modo de vida (RAIMUNDA, A QUEBRADEIRA, 2007).

A atividade de coleta, quebra e beneficiamento do coco babaçu é passada de uma geração a outra e é realizada, predominantemente, por mulheres. Um complemento de renda significativo para suas famílias, principalmente durante o período de entressafra da produção de alimentos. Assim, é perceptível que nessas interações ocorrem mudanças nas dinâmicas das relações sociedade-natureza que, no caso deste estudo, se relacionam diretamente com as estratégias de reprodução social adotadas pelos grupos agroextrativistas da região (RAIMUNDA, A QUEBRADEIRA, 2007).

Para ajudar a entender a rede sociotécnica que expressa às formas de reprodução social do agroextrativismo do babaçu, se faz necessário compreender os aspectos históricos e econômicos do extrativismo do babaçu. Esta é uma atividade secularmente praticada, portanto, portadora de significados econômicos, socioculturais, ambientais, e que faz parte da história de ocupação do Bico do Papagaio. 
A relação entre extrativistas e o babaçu é historicamente marcada pelos múltiplos usos (todas as partes da planta), sentimentalidades (que podem ser percebidas nas poesias e canções populares), religiosidade (por exemplo, a “Ave-Maria das Quebradeiras”), nas representações simbólicas (mãe e virgem). Já a relação de outros atores (geógrafos, indústrias, comércios e governo economistas) com o babaçu só se efetivou a partir do momento em que o babaçu se tornou relevante para a economia.

No encontro dessas histórias houve violências, impasses, conflitos, divergências e negociações. Isto porque as visões destes outros atores sobre o babaçu foram baseadas no paradigma da modernidade, aqui entendida como a ruptura entre o mundo da vida humana e a natureza ou de uma natureza exterior, inteiramente separada do mundo humano ou "por contraste a um passado arcaico e estável", conforme Latour (1994, p. 15). Segundo o autor, esse é um termo, assim como "moderno" e "modernização", que se encontra colocado em meio a uma polêmica, "em uma briga onde há ganhadores e perdedores, os Antigos e os Modernos". Portanto, moderno "é duas vezes assimétrico: assinala uma ruptura na passagem regular do tempo; assinala um combate no qual há vencedores e vencidos” (LATOUR, 1994, p.15).

A modernidade, nessa visão, perpassa a ideia da existência de uma rígida separação entre natureza e sociedade, da dicotomia entre sujeito e objeto e ainda de uma relação de domínio dos homens sobre as coisas do mundo; ideias ditadas pela modernidade, que, na realidade, segundo o autor, são ideias que nunca vingaram plenamente. Essa modernidade criou o Estado e a Empresa como instâncias de representação dos humanos e os laboratórios, as sociedades científicas e instituições de pesquisa como instâncias de representação dos não humanos (LATOUR, 1994).

Considerando que os direitos desses grupos em relação à sua reprodução social e cultural estão fundamentados em anterioridades históricas nos espaços que ocupam (NUNES, 2020), no que toca à necessidade de garantirem a reprodução social de suas famílias, o babaçu, ao lado do trabalho agrícola, a partir do seu uso doméstico, no âmbito familiar, assume um papel importante. Nesse sentido, as dinâmicas relacionadas à questão fundiária envolvendo concentração e/ou grilagem de terras, a pecuária extensiva, as derrubadas de palmeiras de babaçu para plantio de pastagens, ameaçam a sobrevivência dos trabalhadores e trabalhadoras agroextrativistas, além da cultura do território. 
Considerando ainda que a terra e o babaçu são os dois principais elementos para reprodução familiar desses grupos, verifica-se, então, que tais condições acima descritas implicam em limitações e/ou impedimento das atividades agroextrativistas e em significativas mudanças nas dinâmicas das relações sociedade-natureza. Acarreta, ainda, em embates entre os diversos atores relacionados à "questão do babaçu", portanto essas questões merecem atenção, sobretudo, pelo fato de que nas dinâmicas do agronegócio, as lógicas de reprodução social dos grupos sociais em análise são ameaçadas.

\begin{abstract}
Particularmente, na década de 1980, considerada a mais aguda na disputa pela terra na região, a grilagem, a expropriação violenta das famílias, as perseguições e assassinatos de vários posseiros foram práticas correntes, culminando com a morte do Padre Josimo (o "padre preto das sandálias surradas") em 1986, religioso católico que atuava naquela região, cujo assassinato teve repercussão em nível internacional por meio dos meios de comunicação e se tornou um marco na história da região, à semelhança do assassinato de Chico Mendes, no Acre (ROCHA, 2011, p. 30).
\end{abstract}

Como alguns autores têm evidenciado, essa região é marcada por problemas socioambientais que se agravam na medida em que também estão vinculados a situações como o impedimento da atividade do extrativismo do coco babaçu nas áreas das fazendas agropecuárias; a derrubada das palmeiras e envenenamento das pindovas (palmeiras novas); o da sujeição ao proprietário das terras e a uma complexa questão fundiária, que inclui a disputa pela posse e uso da terra entre diferentes atores, induzindo a um ritmo acelerado de uso do espaço e do meio natural (MARTINS, 1985; ALMEIDA, 2000; ALMEIDA, 2008). Sendo assim, a despeito dessa dinâmica, os agroextrativistas vêm se fortalecendo nas últimas décadas, tornando-se importantes atores sociais na região.

Nesse contexto, cabe destacar a luta pelo babaçu livre e a atuação das quebradeiras de coco, cabe destacar a fala da Dona Antônia, Médio Mearim - MA:

O começo do conflito foi a luta pelo coco, foi quando nós fomo proibida de quebrar o coco, aí como nos precisava do coco pra sobreviver, é o coco que nos sustenta, aí nos foi obrigado a reagir, a perder o medo do fazendeiro (ROCHA, 2011, p. 99).

Como forma de reação, as mulheres quebradeiras de coco babaçu assumiram a luta pelo babaçu e pela terra, elegerem a bandeira babaçu livre como instrumento de luta e estabeleceram conexões e vínculos locais e globais. A partir do documentário Raimunda, a Quebradeira (2007), percebe-se o importante papel que as mulheres quebradeiras de coco desempenharam em busca da defesa do babaçu e da terra, o que demonstra uma oportunidade 
de adquirir conhecimento e conhecer outras realidades em busca dos direitos expressos pela Constituição Federal.

O termo babaçu livre é utilizado para fazer referência ao contexto político em que as quebradeiras de coco são as principais atoras, especificamente, está relacionado a busca do direito ao acesso livre às terras com plantações de babaçu, sejam elas públicas ou privadas. Além disso, também inclui a proibição do uso da palmeira com fins predatórios, a derrubada e a queimada, e até o uso de agrotóxicos (RAIMUNDA, A QUEBRADEIRA, 2007).

A expressão "babaçu-livre" tornada bandeira de luta do movimento das quebradeiras, compreende a garantia do pleno acesso das trabalhadoras extrativas aos babaçuais, sem quaisquer interdições. Separa a propriedade do imóvel rural do uso da floresta de babaçu nele incidente (ALMEIDA, 1995, p.12).

Portanto, o babaçu livre representa o direito das quebradeiras de coco ao livre acesso e uso das palmeiras, uma parte da cultura dessas mulheres, passada de geração a geração, o que significa:

Uma "nova concepção" de direito em oposição ao Direito Civil, que privilegia a propriedade privada, como também ao Direito Agrário que impôs o caráter social da terra e não o estendeu a cobertura vegetal, nesse sentido, são falhos para pensar as práticas sociais das quebradeiras de coco babaçu (SHIRAISHI NETO, 2006, p.4).

Durante muitos de anos, grupos de mulheres percorriam os babaçuais, coletando e quebrando coco. Atualmente, tais grupos já não existem mais, e o trabalho de uma mulher que ainda quebra coco é isolado, entre os pequenos povoados e as matas que lhes servem como local de trabalho.

Apesar das mulheres terem um papel importante na unidade familiar agroextrativista, como esposas e mães, responsáveis pela saúde, bem-estar de toda família e, em algumas localidades, sendo responsáveis por $80 \%$ da produção de alimentos da família, elas pouco participam da tomada de decisão. Em muitas iniciativas de desenvolvimento local, elas não são consultadas sobre suas necessidades, sobre os objetivos e sobre a visão de desenvolvimento.

É nessa perspectiva de memória apresentada, uma memória formada pelos grupos, atendendo a interesses e a necessidades específicos, que esse grupo de mulheres quebradeiras de coco da região do Bico do Papagaio, deve ser percebido. Inserido num conflito social, em que o presente destrói um passado com enorme valor simbólico, elas buscam estratégias diferenciadas de resistência para fazer sobreviver a cultura do Babaçu.

Retratar o empoderamento feminino desencadeado pela participação da Dona Raimunda será apreender por meio da memória coletiva, as diversidades e situações vividas por centenas 
de famílias lideradas em sua maioria por mulheres pela garantia da terra e da cultura de seu povo. Na sociedade brasileira, o espaço ocupado pelas mulheres vem crescendo timidamente e o espaço por elas ocupado ainda refletem uma sociedade desigual, embora mais moderna (RAIMUNDA, A QUEBRADEIRA, 2007).

A história da participação feminina na construção da sociedade não ganha a atenção que deveria quando se trata das vivências das quebradeiras de coco do Bico do Papagaio, ou seja, pode-se dizer que se trata de um grupo social pouco expressivo para a sociedade industrializada. Devido a esse fato, existe o risco de ser invisibilizada, sendo esta pesquisa uma forma de documentar essas narrativas e poder colaborar com a sua inserção na memória viva e na cultura da região.

Observando que o cenário atual não se apresenta tão satisfatório como parece, muitos que ali habitam buscam elementos na memória de um tempo em que as relações eram mais harmônicas no sentido ambiental, quando não se tinha necessidade de devastar e queimar para sobreviver, era facilmente conciliável a sobrevivência material das famílias e o bem-estar dos cocais, favorecendo, dentre outras coisas, uma vida mais saudável, oposto do que ocorre atualmente.

Como exemplo, observa-se nos depoimentos gravados no documentário que à medida que as quebradeiras estabeleciam diálogos com outros atores envolvidos na defesa do agroextrativismo, outras dimensões iam sendo incorporadas às suas reivindicações, como os temas relacionados à questão ambiental, política e econômica, porém, todas imbricadas às práticas socioculturais do extrativismo do babaçu (RAIMUNDA, A QUEBRADEIRA, 2007).

\section{CONSIDERAÇÕES FINAIS}

Tratando-se deste estudo, foi proposta uma discussão com foco no extrativismo do babaçu e na participação feminina como marco para as reflexões sobre as dinâmicas das relações sociedade-natureza no Bico do Papagaio - TO. Assim, entre as reflexões, cabe destacar que, quando envolve mulheres que vivem no campo, as diferenças aumentam significativamente, este estudo visa focar o processo de empoderamento feminino a partir da figura de Dona Raimunda, uma quebradeira de coco que vem há décadas ajudando a destacar a participação das mulheres na história da região do Bico do Papagaio e do Tocantins.

A partir das discussões e do documentário, percebe-se que as quebradeiras de coco constroem um discurso identitário em nome de um tempo de abundância diante de um presente 
repleto de novos problemas. As memórias vão ganhando mais forças no decorrer do tempo, da mesma maneira que ganham consistência e força no tempo vivido, representado por uma vida diferente e melhor.

Após 15 anos da gravação e rodagem do documentário Raimunda, a quebradeira foi possível observar que o audiovisual que apresentou através da história de vida e luta de dona Raimunda, história também compartilhada por centenas de outras mulheres quebradeiras de coco, a visibilidade e o foco nas reivindicações pleiteadas pelas mulheres extrativistas do babaçu aumentaram e tornaram os movimentos das mulheres mais fortes.

Diante das discussões empreendidas no documentário, é notável que o grupo de mulheres possuem laços sociais formados a partir do relacionamento com a comunidade local, que trabalham na coleta e outras atividades feitas com o coco em seu cotidiano. Todos auxiliavam na produção, tanto para grupos grandes ou pequenos, era comum a colaboração mútua. Portanto, a vida de um estava entrelaçada à vida dos outros, gerando e mantendo um forte vínculo de fraternidade na comunidade. Esse é o percurso de um grupo de quebradeiras de coco babaçu, o qual enfrenta as mudanças de uma nova era que aparece subjugar o tempo de grande parte de suas vivências tradicionalmente enraizadas na cultura da comunidade.

Para discussões futuras, sugere-se pesquisas voltadas a organização das quebradeiras de coco após a morte da Dona Raimunda, no sentido de compreender o que permaneceu e mudou com a perda da líder. Ainda como sugestão, as discussões teóricas e empíricas podem partir do campo da antropologia, observação participante, pesquisa ação, etnografia, entre outras possibilidades de pesquisa.

\section{REFERÊNCIAS BIBLIOGRÁFICAS}

ALMEIDA, Alfredo Wagner Berno de. (Org.). Economia do babaçu: levantamento preliminar de dados. São Luís: MIQCB, 2000.

ALMEIDA, Alfredo Wagner Berno de. Quebradeiras de coco babaçu: identidade e mobilização: legislação específica e fontes documentais e arquivísticas (1915-1995). São Luis: MIQCB, 1995. 183p.

ALMEIDA, Alfredo Wagner Berno A. W. B. de. Terras de Quilombo, terras indígenas, "babaçuais livres", "castanhais do povo", faxinais e fundos de pasto: terras tradicionalmente ocupadas. 2 Ed. Manaus: PGSCA-UFAM, 2008. 


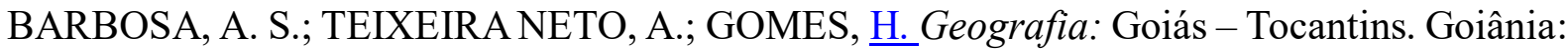
UFG, 2004.

BERGSON, Henri. Matéria e memória. Trad. Paulo Neves. $2^{\mathrm{a}}$ ed. São Paulo: Martins Fontes, 2009.

BOSI, Ecléa. Memória e sSociedade: Lembranças de Velhos. 18 ed. São Paulo: Companhia das Letras, 2015.

BOTELHO, Milena Azevedo Lena. Narrativa e memória: o trabalho das quebradeiras de coco da região do Bico do Papagaio em "Raimunda a "quebradeira". 2020. 125f. Dissertação (Mestrado em Comunicação e Sociedade) - Universidade Federal do Tocantins, Programa de Pós-Graduação em Comunicação e Sociedade, Palmas, 2020.

BRITO, Eliseu Pereira de; ALMEIDA, Maria Geralda de. Sentido e organização do trabalho das quebradeiras de coco no Bico do Papagaio, Tocantins. Geosul, v. 32, n. 63, p. 229-249, 2017. BRITO, E. P. de.; ALMEIDA, M. G. de. Sentido e organização do trabalho das quebradeiras de coco no Bico do Papagaio, Tocantins. Geosul, v. 32, n. 63, 2017.

CAMURÇA, S. Nós mulheres e nossa experiência comum. Reflexões para transformação social. Cadernos de Crítica Feminista, v. 1, n. 1, Recife, dez. 2007.

CLEMENTINO, Alessandro Medeiros; MONTE-MÓR, Roberto Luís M. Grandes Projetos e seus impactos e significados na Região do Bico do Papagaio - TO. Anais, pp. 1-16, 2016.

COMISSÃO Mundial Sobre Meio Ambiente E Desenvolvimento (CMMAD). Nosso futuro comum. Rio de Janeiro: Fundação Getulio Vargas, 1991.

COSTA, Ana Alice Alcantara. O movimento feminista no Brasil: dinâmicas de uma intervenção política. Revista Gênero, [s.1.], v. 5, n. 2, pp.1-20, 19 fev. 2013.

COURTINE, Jean-Jacques. Le tissu de la mémoire : quelques perspectives de travail historique dans les sciences du langage. Langages, Paris, 1994, pp. 5-12, 1994.

DAVIS, Angela. Mulheres, raça e classe. Tradução Heci Regina Candiani. São Paulo : Boitempo, 2016.

DIAS, Luciene de Oliveira. Mulheres de fibra: estratégias das quebradeiras de coco babaçu no Tocantins como um marco empírico para o desenvolvimento sustentável. 2005. 87f. Dissertação (Mestrado em Ciências do Ambiente) - Universidade Federal do Tocantins, Programa de Pós-Graduação em Ciências do Ambiente, Palmas, 2005.

DIEHL, Astor. A cCultura hHistoriográfica: memória, identidade e representação. Bauru: EdUSC, 2000. 
DUVERNOY, Isabelle. Diagnostic de la perennisation de l'activité agricole dans la fronteire agraire de Misiones (Argentine): une methode de généralisantion spatiale. 1994. 198f. Tese (Doutorado) - INRA-SAD, Touloube França, 1994.

FOWERAKER, Joe. A luta pela terra: a economia política da fronteira pioneira no Brasil de 1930 aos dias atuais. Tradução de Maria Júlia Goldwasser. Rio de Janeiro: Jorge Zahar, 1982. $315 \mathrm{p}$.

FURTADO, Celso. O mito do desenvolvimento econômico. Rio de Janeiro: Paz e Terra, 1974.

GEERTZ, Clifford. O saber local. Tradução de Vera Mello Joscelyne. 5. ed. Rio de Janeiro: Vozes, 1997.

GIL, Antônio Carlos. Como elaborar projetos de pesquisa. 4 ed. São Paulo: Atlas, 2002. $176 \mathrm{p}$.

GOMES, Mércio Pereira. Antropologia: ciência do homem: filosofia da cultura. 2. ed. São

GONZÁLEZ-PÉREZ, Sol Elizabeth; COELHO-FERREIRA, Márlia; DE ROBERT, Pascale; GARCÉS, Claudia Leonor López. Conhecimento e usos do babaçu (Attalea speciosa Mart. e Attalea eichleri (Drude) AJ Hend.) entre os Mebêngôkre-Kayapó da Terra Indígena Las Casas, estado do Pará, Brasil. Acta Botanica Brasilica, Belo Horizonte, v. 26, n. 2, pp. 295 308, abr./jun. 2012.

HALBWACHS, Maurice. A memória coletiva. São Paulo: Vértice, 1990.

HARTSOCK, Nancy. The Feminist Standpoint: Developing the Ground for a Specifically Feminist Historical Materialism. In: HARDING, Sandra; HINTIKKA, Merrill B (Eds.).

HÉBETTE, Jean.; ACEVEDO, Rosa Elizabeth. Colonização para quem? Belém: NAEA/UFPA, 1979.

HOMMA, Alfredo. Kingo. Oyama. Extrativismo vegetal na Amazônia: limites e oportunidades. Empresa Brasileira Pesquisa Agropecuária, Centro de Pesquisa Agroflorestal da Amazônia Oriental. Brasília: EMPRAPA SPI, 1993.

JALIL, Laeticia. Soberania Alimentar, feminismo e ação política. Agriculturas, Rio de Janeiro, v. 6, n. 4, pp. 9-11, dez., 2009.

KOPENAWA, Davi.; ALBERT, Bruce. A queda do céu: pPalavras de um xamã yanomami. São Paulo: Editora Companhia das Letras, 2015. 
LAMPOGLIA, Francis; ROMÃO, Lucília Maria Sousa. Na cela: considerações sobre sentidos inscritos em cartuns de Angeli. Revista Galáxia, São Paulo, n. 19, pp. 252- 262, jul. 2010.

LATOUR, B. Jamais fomos modernos: ensaio de antropologia simétrica. Tradução de Carlos Irineu da Costa. Rio de Janeiro: Ed. 34, 1994. 152 p.

LE GOFF, Jacques. História e memória. 3 ed. Campinas: Editora da UNICAMP, 1994.

LEITE, Sérgio Pereira. et al. Impacto dos assentamentos: um estudo sobre o meio rural brasileiro. Brasília: Nead; São Paulo: Editora Unesp, 2004.

LENA, M. B. A.; PÔRTO JÚNIOR, F. G. R. O olhar da imprensa frente a luta das mulheres quebradeiras de coco da região do bico do papagaio. In: Media effects: ensaios sobre teorias da Comunicação e do Jornalismo - Espiral do silêncio, enquadramento e contemporaneidade. PÔRTO JÚNIOR et al. (Orgs.). 3 Ed. - Porto Alegre, RS: Editora Fi, Boa Vista, RR: EdUFRR, 2018.

LENA, Milena. Botelho. A.zevedo; PORTO JUNIOR, Francisco. Gilson. Rebouças. As quebradeiras de coco babaçu e as suas estratégias de luta e mobilização. In: SANTI, Vilso Júnior Chierentin et al. (Org.). Povos originários e comunidades tradicionais: trabalhos de pesquisa e de extensão universitária. 6 Ed. Porto Alegre, RS: Editora Fi, 2020, v. 6, pp. 187-206.

MARTINS, Cynthia Carvalho. Agricultura e garimpo na lógica camponesa: os deslocamentos como categoria de análise. 2000. 222 f. Dissertação (Mestrado) - Curso de Mestrado em Políticas Públicas, Universidade Federal do Maranhão, São Luís, 2000.

MARTINS, José de SouzaJ. de S. A Militarização da Questão Agrária no Brasil (Terra e poder: o problema da terra na crise política). Petrópolis: Editora Vozes, 1985.

MARTINS, José de Souza. Fronteira: a degradação do outro nos confins do humano. São Paulo: Hucitec, 1997.

MCLAREN, Margaret A. Foucault, Feminismo e Subjetividade. São Paulo: Intermeios, 2006.

MIRANDA NETO, Manoel. José. O enigma Amazônia: desafio ao futuro. Belém: CEJUP, 1991. 144p.

NETO, Joaquim Shiraishi. Quebradeiras de coco: "babaçu livre" e reservas extrativistas. Veredas do Direito: Direito Ambiental e Desenvolvimento Sustentável, v. 14, n. 28, pp. 147-166, 2017.

NUNES, Marcela Luana. Sampaio.;. Terra, cultura e coletividade: proteção dos saberes e práticas tradicionais das quebradeiras de coôco babaçu. E-Civitas, v. 13, n. 2, pp. 246-262, 2020. 
ORLANDI, Eni P.ulcinelli; RODRIGUES, Suzy Lagazzi (Org.). Introdução às ciências da linguagem: discurso e textualidade. Campinas: Pontes, 2006.

PACÍFICO, Soraya Maria Romano; ROMÃO, Lucília Maria Sousa. A memória e o arquivo produzindo sentidos sobre a trajetória da mulher. Em questão. Porto Alegre, v. 12, n. 1, p.7390, jan./jul. 2006.

Paulo: Contexto, 2015.

PÊCHEUX, Michel. Ler o arquivo hoje. In: ORLANDI, Eni Pulcinelli (Org.). Gestos de leitura. Campinas: Unicamp, 1982.

PIZZIO, Alex; CECCHIN, Hareli Fernanda Garcia. PIZZIO, A.; CECCHIN, H. F. G. O Movimento Interestadual das Quebradeiras de Coco Babaçu na região do Bico do Papagaio: reflexões sobre justiça social. Revista Brasileira de Desenvolvimento Regional, v. 3, n. 2, p. 111-133, 2015.

PLANO Territorial De Desenvolvimento Rural Sustentável: Território Da Cidadania Baixo Tocantins. Belém, 2007. Disponível em: http://sit.mda.gov.br/download/ptdrs/ptdrs_qua_territorio130.pdf. Acesso em: 04 out. 2021.

POLLAK, Michael. Estudos Históricos: Rio de Janeiro, vol. 2, n. 3, 1989.

PRODANOV, Cleber Cristiano; DE FREITAS, Ernani Cesar. PRODANOV, C. C.; FREITAS, E. C. de. Metodologia do trabalho: métodos e técnicas da pesquisa e do trabalho acadêmico. 2 ed. Novo Hamburgo: Feevale, 2013.

Raimunda, a Quebradeira. Direção: Marcelo Silva. Public Propaganda \& Marketing, Palmas, Tocantins, Brasil, TV PALMAS REDESAT TOCANTINS, 2007. YouTube.

ROCHA, Maria Regina Teixeira da. A rede sociotécnica do babaçu no Bico do Papagaio (TO): dinâmicas da relação sociedade-natureza e estratégias de reprodução social agroextrativista. 252p. 2011. Tese (Doutorado em Desenvolvimento Rural) - Universidade Federal do Rio Grande do Sul, Faculdade de Ciências Econômicas, Programa de PósGraduação em Desenvolvimento Rural, Porto Alegre, 2011.

SACHS, Ignacy. Caminhos para o Desenvolvimento Sustentável. 2. ed. Rio de Janeiro: Garamond, 2002. 96 p.

SADER, Maria Regina Cunha de Toledo; GOLDENSTEIN, Léa. Espaço e luta no bico do papagaio. São Paulo: Universidade de São Paulo, São Paulo, 1987.

SANTOS, Antônio. Bispo. Colonização, Quilombos: modos e significados. Brasília: Instituto Nacional de Ciência e Tecnologia de Inclusão no Ensino Superior e na Pesquisa, 2015. 
SANTOS, Raimundo Lima dos. Associação, memória e luta das quebradeiras de coco no Maranhão: o povoado de Petrolina. MÉTIS: história \& cultura, v. 8, n. 15, p. 49-65, 2009.

SARAIVA, A. F. da.; OLIVEIRA, N. M. de; PEDROZA FILHO, M. X.; LOPES, W. S. Cadeia produtiva do babaçu em Cidelândia-MA: uma análise a partir da abordagem de cadeia global de valor. Revista Brasileira de Gestão e Desenvolvimento Regional, v. 15, n. 2, 2019.

SEN, A. K. Desenvolvimento como Liberdade. São Paulo: Companhia das Letras, 2000.

SHIRAISHI NETO, Joaquim. Quebradeiras de coco: "babaçu livre" e reservas extrativistas. Veredas do Direito: Direito Ambiental e Desenvolvimento Sustentável, Belo Horizonte, v. 14, n. 28, p. 147-166, jan./abr. 2017.

SOARES, Zaré Augusto Brum. Agricultura familiar, movimentos sociais e desenvolvimento rural na região do Bico do Papagaio, Tocantins: um estudo sobre as relações entre sociedade civil e desenvolvimento. 2009. 188 f. Dissertação (Mestrado em Ciências Sociais em Desenvolvimento, Agricultura e Sociedade) - Instituto de Ciências Humanas e Sociais, Universidade Federal Rural do Rio de Janeiro, Seropédica - RJ, 2009.

SWERTS, Leila Afonso. Políticas de desenvolvimento, organização do território e participação: as quebradeiras de coco babaçu na microrregião do Bico do Papagaio, Tocantins. 2009. 167 f. Dissertação (Mestrado) - Curso de Mestrado em Geografia, Universidade de Brasília, Brasília, 2009.

TOSCANO, M.; GOLDENBERG, M. A Revolução das mulheres: um balanço do feminismo no Brasil. Rio de Janeiro: Revan, 1992.

VIVEIROS DE CASTRO, E. Os involuntários da pátria: elogio do subdesenvolvimento. Revista Chão de Feira, Série Intempestiva, n. 65, pp. 1-9, 2017.

Artigo recebido em: dezembro/2021

Artigo aceito em: fevereiro/2022 